\title{
Colors of Peace
}

\author{
Indira Y. Junghare \\ University of Minnesota, Minneapolis, USA
}

\begin{abstract}
In this age of modernization and mechanization, we seem to have lost sensitivity to a collective awareness regarding the welfare of our surroundings, people, animals, microbes, and plants. We seem to encounter systemic problems of corruption, moral bankruptcy, and spiritual decay. This leads to a rise in violence at various levels: individual, familial, societal, global, environmental, and biological. In order to combat these problems, it is necessary to examine the diverse semantics of the concept of peace: positive peace, negative peace, world peace, socio-cultural peace, and individual peace. The semantics of peace changes according to the context, for example, "May he rest in peace," is quite different from: "His beautiful memories will give you peace." Since society is constituted of a group of persons, an individual becomes society's substantive foundation with his/her conscious self, made of mind, body and spirit. The individual with creative power can become an agent of positive change. Using the interdisciplinary socio-linguistic/semantic and humanistic-philosophical approaches, this paper analyzes the "all-inclusive" and "interdependent" nature of life and the role and power of the individual (self) in the creation of peace at diverse levels: personal, community, the globe, and the cosmos. The paper draws heavily from India's spiritual worldview and humanistic techniques in resolving conflicts and attaining freedom from ill-health for peaceful living.
\end{abstract}

Keywords: peace, violence, physical, mental, spiritual, self, globe, change

\section{Introduction}

The concept of peace is abstract; therefore, it is subjective to diverse translations and interpretations. This depends upon the subject's worldview, inclusive of his socio-political-religious philosophy, his/her upbringing and experiences in the context of environment: familial, communal, regional, national, international, and global. From a linguistics view point, all languages and their representative cultures evolve over time, giving rise to diversity of people, differing needs of life, and the development of new ideas and new vocabularies related to the changing nature of life, fitting to the modern industrialized and mechanized world of drones, bombs and nuclear power. All life of the planet is in peril with industrial pollution leading to the destruction of various species, including humans.

The problems of adaptation and acculturation have been difficult to resolve due to diverse populations, but more so for the weak and the powerless, such as women, minorities, older, younger, and people of diverse ethnicities, i.e. people of different traditions, religions and cultures. This era is plagued by war, violence, aggression, oppression, greed, increased materialism, individualism, abuse of resources, loss of biodiversity, and the loss of morality and ethics. This has been causing a great deal of suffering at all levels of life: physical,

Indira Y. Junghare, Ph.D., Professor, Institute of Linguistics, University of Minnesota.

Correspondence concerning this article should be addressed to 1768 Lake Street, St. Paul, MN 55113, USA. 
psychological, spiritual, socio-political, and global. In this paper, we explore various aspects of the concept of peace with the semantic and cultural-linguistic viewpoints in relation to diversity of life and its broader understanding.

The purpose of this paper is not to test any conceptual model, but to show how the concept of peace is understood and used differently by different people, individually or collectively, in diverse situational contexts. Finally, the paper proposes the need to understand the diversity of life, because not only the world is multifaceted, but we as individuals too are of different compositions-physically, mentally, and spiritually - constantly changing in time and space. Yet, we are connected on some level, and when something bad happens, it affects us all. For peaceful coexistence, the paper proposes the philosophy of diversity, the substratum of which is "oneness" of life through connectivity and inter-dependence, requiring mutual recognition, and respect.

\section{Concepts of Peace}

Generally speaking, the concept of "peace" is understood as world peace. World peace is an idea of planetary non-violence by which nations willingly cooperate, either voluntarily or by virtue of a system of governance that prevents warfare. For example, since 1945, the United Nations and the five permanent members of its Security Council (US, Russia, China, France, and the UK) have worked to resolve conflicts without war or declarations of war. However, many nations have entered numerous military conflicts since that time. And so this begs the question: What causes people to have conflict? Why do we fight? The important thing about the concept of peace is that it is relational. It is understood and used differently by different people in diverse situational contexts.

Peace in general, is a period of harmony between different social groups that is characterized by lack of violence or conflict behaviors, and the freedom from fear of violence. Commonly understood as the absence of hostility and retribution; peace also suggests sincere attempts at reconciliation, and the establishment of equality and respect, through which a working political order is established that serves the true interests of all. ${ }^{1}$

\section{Peace as Absence of War}

Wars, conflicts, invasions, and territorial occupations have been known to mankind from ancient times. Similarly, efforts to maintain peace have been present at all times. The 20th century was the most violent in human history. In response, numerous trends, global collaboration, constructive conflict resolution, and social changes have occurred. Various non-governmental organizations and supra-national institutions have been formed since 1945 with the goal of attempting to prevent war through negotiations, sanctions, and collective security. The European Union, the Organization of American States, and the African Union monitor regional disputes and engage in peace-making and peace-building activities. The U.S. exploded the first atomic bomb on the 16th of July 1945 in New Mexico. Since then nearly 2,000 bombs have been exploded globally. Hence, in 1996, the Nuclear Test Ban treaties banned all atomic explosions in the atmosphere, on the water, and on the ground. ${ }^{2}$

\footnotetext{
${ }_{1}^{1}$ https://en.wikipedia.org/wiki/Peace. Accessed October 26, 2015.

$2 \mathrm{https} / / /$ en.wikipedia.org/wiki/Comprehensive_Nuclear-Test-Ban_Treaty. Accessed October 26, 2015.
} 


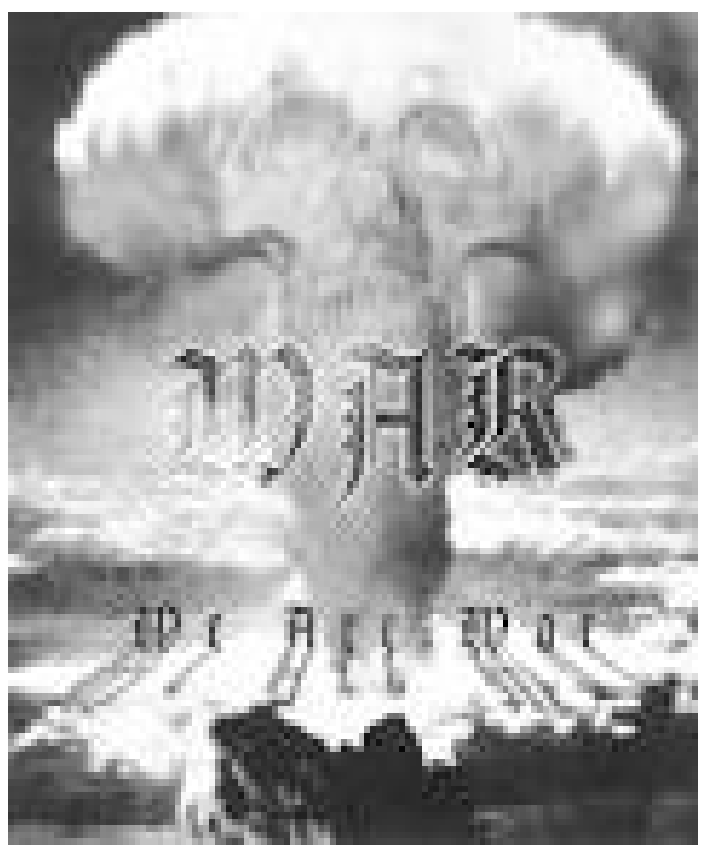

Figure 1. Vietnam-war-1965 (Nuclear Explosion). Source: http://www.google.com/Vietnam war+symbols.

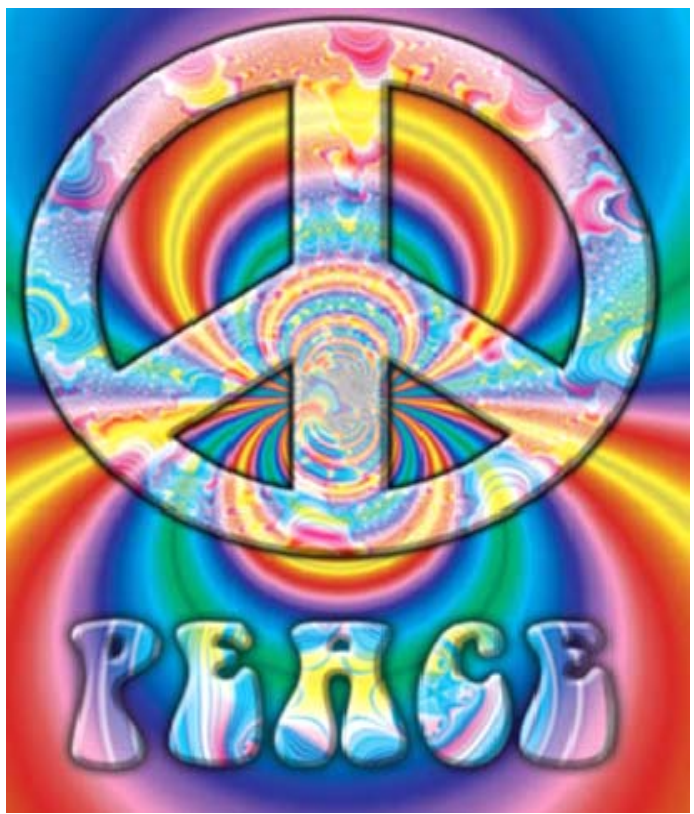

Figure 2. International Peace Symbol (Nuclear Disarmament). Source: https://en.wikipedia.org/wiki/Peace symbols.

\section{Diverse Semantics of Peace}

Often, the semantics of the concept and its word meaning can be understood by its antonym. The word opposite of PEACE is violence. The word violence originated during 1250-1300 in Middle English from Anglo-French, Old French, Latin violentia. "vehemence, impetuosity." It meant "swift and intense force, injurious physical force, action, or treatment". Also, it meant unwarranted exertion of power, as against rights

\footnotetext{
${ }^{3}$ http://dictionary.reference.com/browse/peace. Accessed October 26, 2015.
} 
or laws. However, the concept of "peace" evolved over centuries and in different regions of the globe producing different meanings.

Some scholars of peace studies, following Wolfgang Dietrich (2012) and the Innsbruck School of Peace Studies (Dietrich, Echavarria, \& Koppensteiner 2006, pp. 282-305) have abandoned any single and all-encompassing definition of peace. Rather, these scholars promote the idea of many peaces. They argue that since no singular, correct definition of peace can exist, peace should be perceived as a plurality. Many different theories of "peace" exist in the world of peace studies, which involves the study of conflict transformation, disarmament, and cessation of violence. This idea of the plurality of peace has been supported by diverse opinions of socio-political leaders of diverse ethnicities who fought for freedom from foreign dominion, slavery, and subjugation in order to attain peace, examples being Mahatma Gandhi, Martin Luther King, Jr., and Nelson Mandela, etc.

Similarly, the definition of "peace" can vary with religion, culture, or ethnicity. The following quotes are examples, obtained through interviews carried out in the months of May and June of 2015.

The contemporary world, characterized by unstructured mixture of values, is a world in which peace and war intermingle with each other. In this world, the entire history, both of the great peacemakers and of the bravery, is seen through the fog. The only peace that clears eyes is inner peace. (Romanian scholar)

Peace for me is internal calmness of the body. Also, peace means calmness in the globe and nature and harmony in the relationship between humans and nature. (Chinese physician)

Being content within oneself is peace. Also, accepting of one's shortcomings and weaknesses and forgiving oneself for the past wrong doings. (American teacher)

Peace means coexistence with acceptance and tolerance of all sorts of diversity. (American scholar)

The meaning of universal peace means "contentment" which lies in the proper appropriation of our inner energies. Peace is the "strength" to forgive oneself and others. Peace lies in liberty. Every being wants to be free from pain and suffering, caused by ill-health due to biological and socio-cultural environments. (Indian scholar)

\section{Peace and Philosophy of Religion}

Philosophies of religions often attempt to address the problems of human life: conflicts within, among, and between persons and societies. In Christianity, Christ, the Son of God, was to establish God's kingdom of peace and heal all of creation, people and societies from evil. In Islam, people believe that only Allah the God is the source of peace. In Buddhist thought, life is a perpetual cycle of suffering; peace can be attained when all suffering ends and through the understanding of Four Noble Truths and the practice of Eightfold-Path. ${ }^{4}$ In Hinduism, the concept of peace is broad and all-inclusive:

May there be peace in the heavens, peace in the atmosphere, peace on the earth. Let there be coolness in the water, healing in the herbs and peace radiating from the trees. Let there be harmony in the planets and in the stars, and perfection in eternal knowledge. May everything in the universe be at peace. Let peace pervade everywhere, at all times. May I experience that peace within my own heart-Yajur Veda 36.17. (Witzel, 2003, pp. 76-77)

\section{Peace, Liberty and Justice}

Since classical times, it has been noted that peace has sometimes been achieved by the victor over the vanquished by the imposition of ruthless measures. However, this concept has been debated on the grounds of

\footnotetext{
${ }^{4}$ https://en.wikipedia.org/wiki/Peace.
} 
morality. Peace must be seen at least in two forms: absence of war; and absence of war accompanied by terms as justice, mutual respect, respect for law and good will.

More recently, advocates for radical reform in justice systems have called for a public policy adoption of the non-punitive, non-violent Restorative Justice method, and many of those studying the success of these methods, including a United Nations working group on Restorative Justice, have attempted to re-define justice in terms related to peace. From the late 2000s on, a "Theory of Active Peace" has been proposed which conceptually integrates justice into a larger peace theory (Wilmerding, 2010). Additionally, Johan Galtung (1996), one of the pioneers of the field of peace research, who promoted the theory of peacemaking, peacekeeping and peace building, considered peace as part of a triad, which includes justice and wholeness (or well-being). However, in reality, the system of justice has not really been incorporated into the restorative system of peace, as can be seen from the following tale aired in terms of interviews (60 Minutes, CBS; Sunday, October 11, 2015).

Glenn Ford, a young man of Afro-American ethnicity, was wrongfully convicted of murder and sentenced to death. He spent 30 years on death row, in solitary confinement, in Louisiana's notorious Angola prison until new evidence revealed he did not commit the murder. The maximum-security prison has a well-earned reputation for harsh penalties and harsher conditions. Summer temperatures on death row commonly exceed 104 degrees. A court review of the new information found that Glen Ford was neither present at, nor a participant in, the robbery and murder of Isadore Rozeman. Last year, Ford was exonerated and released from Angola. When Bill Whitaker asked Ford, "What was it like to step outside the walls of that prison?" Glenn Ford answered, "Like stepping in a brand new world; like breathing fresh air for the first time. It felt good."

Shortly after being released, Ford learned he had stage IV lung cancer. Doctors told him he had only a few months to live. After his release, Ford was given a $\$ 20$ gift card in compensation for his 30 years of incarceration; with that amount, he could eat only one meal. Three months later, by the time the interview was aired, Mr. Glenn Ford had died. Mr. Ford was robbed of his human dignity through violations of human rights. Justice has not been served.

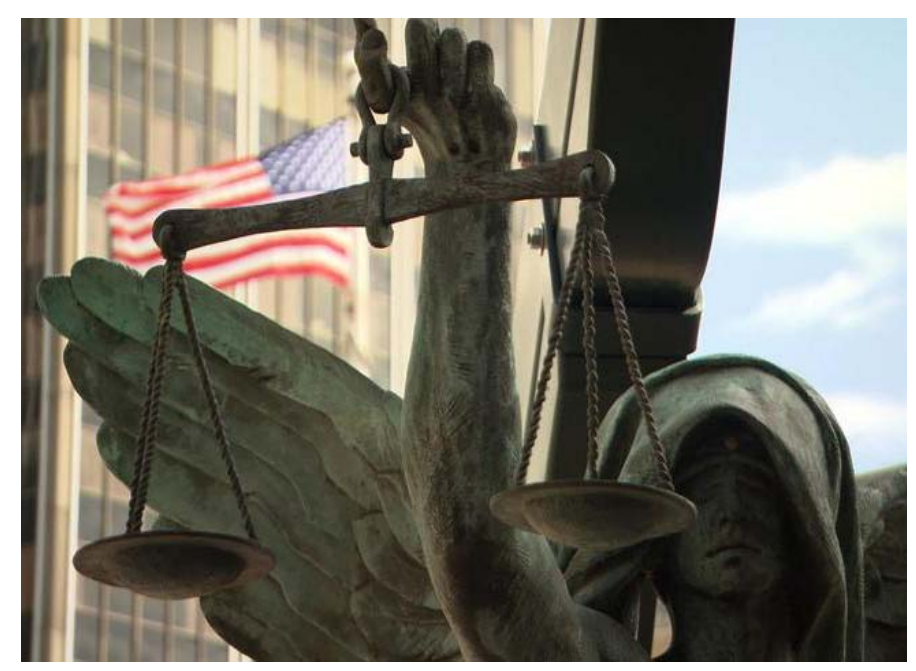

Figure 3. Lady Justice, Shreveport, CBS News. 


\section{Diverse Faces of Justice and Peace}

It is necessary to recognize that not only peace but also conflict is relational. What we mean by this is that everybody has his/her own perspective; own value system, and own viewpoint regarding other people. Individuals' conducts are shaped by their socio-cultural traditions, their experiences, and the required and expected obligations of their professions. For example, the public prosecutor said Louisiana should "kill more people". Furthermore, he justified his role by saying, "I am not in the compassion business; none of us as prosecutors or defense lawyers are in the compassion business." On the other hand, Glenn Ford's court-appointed defense lawyer Marty Stroud said, "It was a train to injustice, and I was the engineer. Derailing someone's life is not acceptable 'justice'. Glenn Ford will be a part of me until the day I die."

\section{Cultural Relativism}

The case above clearly indicates a different number of perspectives in promoting peace as it relates to the concept of justice. Therefore, each culture, each society, and each discipline must be evaluated in terms of its own internal structures, values, and presuppositions. The fallacy of the usual approach is attempting to explain all of reality from the narrow perspective of just one discipline, which is usually one's own.

The consequences of this fallacy are conflicts, war, violence, and abuse between people. When we widen the scope of conflict to an even more global scale, we see that animals and nature sometimes get pushed aside and disrespected in favor of humanity because we tend to see ourselves as evolutionarily superior when of course this is not the case. Bagish (1990, p. 34; quoted from Rosado, 1994, pp. 6-7) claims that this is not an ethnocentric perspective, but a pragmatic principle of choosing the one that works better than that which does not work.

It means that any belief or practice that enables human beings to predict and control events in their lives, with a higher degree of success than previous beliefs or practices did, can be said to "work better". Better prediction and better control of events - those are the two essential ingredients that enable human beings to adapt better to the world around them. (Bagish, 1990, p. 34; quoted from Rosado, 1994, p. 7)

This essentially means better working policies and practices should be chosen over non-working ones, because not all cultural practices and values are sound or of equal value and worth. Furthermore, it is necessary to realize that "culture is not the only or primary factor in human experience; it is but one essential condition of human experience" (Bidney, 1959, p. 67; quoted from Rosado, 1994, p. 8). This implies that culture is not absolutely autonomous and independent and that "all modes of human experience and thought are relative thereto, because they are functions of culture and dependent on it for their form and content" (Bidney, 1959, $p$. 66; quoted from Rosado, 1994, p. 7).

\section{Elitism/Humanism—Laws}

People with education and money are considered to be elites. People have valued elitism, especially in urbanized centers and developed cities, because they can initiate progressive movements. However, it creates class conflicts, because elites hold power in making decisions, policies and laws, which tend to guard their own interests and not necessarily guard the welfare of the middle and lower classes. This phenomenon holds more true in democratic cultures. There seems to be a great deal of disparity between the elites who make up only $1 \%$ 
of the entire population in the U.S. President Kennedy said that only 50 men ruled America. We know a woman president has not yet appeared.

\section{Why Diverse Facets of Peace?}

In the 19th century, linguists adopted an evolutionary paradigm in accordance with which it was not merely conceded but expected that words would change continually in sound, form and meaning. This new acceptance of change gave rise to diachronic (historical development) and synchronic (present) linguistics. The broad semantic development of the concept of peace from community to individual, from outer to inner, and from innate to relational is due to diachronic and synchronic linguistics. Not just people but also languages, words, and ideas change over time. In light of this scholarship, the word "peace" represents different evolutionary shades of meanings. ${ }^{5}$

\section{Philosophy, Religion and Science: Disciplinary Relatives}

Reality can be looked at and interpreted differently: philosophically, religiously, or scientifically. Science is only one way. It is based upon the assumption that knowledge can be free of any cultural bias and it can explain the actual workings of the empirical world, and that it can be revised by conducting more experiments or empirical testing (Turner, 1986; Herskovits, 1973; Rosado, 1994). However, this view of science is inaccurate because no one views the world objectively. The truth is that the subject cannot become the object. Reality is that most things are dependent upon our mind. According to the Yogacara school of Indian philosophy, "Mind is the only reality" (Eliade, 1958; Puligandla, 1975). Even the questions that we raise about our world are based on our experiences which are shaped in the context of our cultural environment. This suggests that our knowledge of the world comes to us from different sources, science being one, philosophy another, and religion is yet another.

For philosophers, logic and metaphysics are the methods, while for religious people, divine revelation serves as the source; to them sacred books, such as the Bible, the Bhagavad-Gita, the Torah, or the Koran provide diverse cultural values. Even here, these sacred books, like other realities, are to be understood by human beings through their own cultural experience (Rosado, 1994). Thus, language in both forms, spoken and written, is a product of culture and expressive of the needs of people belonging to that culture.

In the 21 st century, everyone is expected to become a citizen of the globe, which is inclusive of diverse cultures and diverse ethnicities. Therefore, one is left with no choice but to transcend one's gender, race, ethnicity and socio-political reality and connect with others on the grounds of common human needs for existence and life-sustaining principles-love, compassion, and tolerance. "Thus, cultural relativism, as a new way of seeing, is a necessary optic to perceive the socio-cultural reality in today's multicultural, world society" (Rosado, 1994).

\section{Humans and Nature: Biological/Physical Connectivity}

As scientific and spiritual fields continue to develop broader understandings of our existence, one thread continues to connect humanity: the appreciation of natural biodiversity stemming from evolution. As over-consumption runs rampant in modern society, it is important to consider the environmental conservationist argument as stated by Wilson:

\footnotetext{
${ }^{5}$ http://dictionary.reference.com/browse/peace.
} 
Life on this planet can stand no more plundering. Quite apart from obedience to the universal moral imperative of saving the Creation, based upon religion and science alike, conserving biodiversity is the best economic deal humanity has ever had placed before it since the invention of agriculture. (Wilson, 2006, p. 99)

The easiest area to reconcile our intuitive spirituality and logical scientific minds in is the natural human connection to our planet's wide variety of life forms. This divine diversity is considered "the creation" by several religions, but also as "nature" by science. In appealing to the inner connection with the natural world, the biological theory of evolution can coexist peacefully with the world's religions.

\section{Humans, Animals, Plants and Microbes: Diverse Perspectives}

Both science and religion start with basic assumptions that are subjective. In the sciences, theories are tested with observable facts and scientific experiments. Additionally, science and religion differ in language. Many social scientists reject the divine aspect of religion, since the God does not fit the parameters of an empirical approach. The problem is that each discipline uses its norms to evaluate the findings of another discipline. Here we need to understand the fact that different disciplines use different methods and that each must be evaluated on its merits. This concept of relativism applies to diverse ethnic cultural groups as well. People's perception and "judgments are based on experience, and experience is interpreted by each individual in terms of his or her own enculturation" (Herskovits, 1973, p. 15). It is simply the process by which a culture is learned. This is because much of human knowledge tends to be socially conditioned. People in different social positions and cultural settings think differently. To quote from the Jainism's perception theory, "syādavād: Where you stand determines what you see!" This theory is known as the doctrine of relativity of knowledge and judgment (syād—relative to some standpoint, vāda—doctrine, theory, view). The problem with this doctrine, however, is that all talk of relativity makes sense only in the light of some absolute, real or imagined (Puligandla, 1975, p. 45).

The theory of cultural relativism then explains the diversity of the concept of peace related to his/her/it's worldview, struggle, conflicts, and oppression caused by others: the communities, institutions, and by socio-political-economic conditions and suffering due to biological, physical and mental conditions i.e. disease, illness and death. Given unpredictable and insurmountable problems of life, all we can do is to teach people intercultural relativism based on the observable and universal rather than from the perspective of absolute ethics.

\section{Peace, Ethics and Rights of Existence}

Most systems of ethics are somewhat anthropocentric. Anthropocentrism focuses on human beings as the center of existence. Some systems contain elements of biocentrism, the belief that the rights and need of humans are not more important than those of other living things. Similar to evolutionary ethics, follows the idea that plants, animals and humans were formed by the same evolutionary process and are therefore, equal. It also emphasizes symbiotic relationships. We are all knots in the web of life. However, because we are all equal, we have no more moral obligation to protect biodiversity than any other plant or animal. This approach is biocentric, but anthropocentric upon a second look. One could argue that Homosapiens is the ultimate organism. We have successfully competed against most life on the planet with the exception of viruses and bacteria. We also have the ability to inhabit any biota. We have also developed other agents, such as pesticides and antibiotics, to wipe out our competitors. Although naturalism praises the value of every form of life, it also states that we have no moral obligation to protect biodiversity, implying that humans are entitled to the fruits of 
this earth because we have somehow earned it through superior evolutionary processes.

\section{Humanism and Ethics}

According to Kantian (1999) and Indian-Buddhist philosophy, ethics is unique to rational beings. Rational beings are capable of formulating universal truths of mathematics, science, and so on. Because of man's ability to rationalize, Kant theorized that one must treat all human beings as "ends in themselves", not merely as means, as possessing "intrinsic value", not instrumental value. Essentially, this ethical principle forces the society to behave morally. A human being is not a tool to be used and thrown away. He is valued for what he is-for his reason. He is valued for his intrinsic (positive and negative) attributes and not how well he serves the society and how little others value him. Thus, he is an "end in himself".

Both theories have their own drawbacks. Utilitarianism does not protect the welfare of an individual, while Kantian rationalism somewhat ignores the welfare of society. Hence neither qualifies for an ideal practicable social ethic. Despite their problems, Rollin (2006, p. 64) claims that the theory behind American socio-cultural ethics represents a middle ground or synthesis between utilitarian and Kantian theories - a combination of political philosophy of democracy, capitalism and humanism (human rights).

\section{Inner Peace}

Life is marked by conflicts at all levels, international, national, communal, and personal or individual. As William Shakespeare's Hamlet said: "To be? Or not to be?" Generally, people choose to exist despite life's problems and try to handle them to the best of their capacities. As for the individual person, there is a conflict between mind and body. Mind and body are perceived as separate in Western philosophical thought. However, the mind is part of the brain that does the thinking. Additionally, there is a deep consciousness, which has been labeled as spirit or soul which energizes both. In order to be in good health, an individual has to maintain the balance or harmony between body, mind and spirit.

The West focused on the external side of the cosmos and man, giving importance to matter. On the other hand, both the religious and secular philosophies of India focused on the mind, especially its changing modalities and their web-like connectivity comparable to cosmic elements and outer forces. Metaphysics in these philosophies is closer to physics. Though we humans can neither completely predict moods of nature nor prevent disasters, we can partially control body-mind-spirit harmony which translates into inner peace.

\section{Means and Methods of Achieving Peace}

Since the concept of peace is paradoxical and relational, i.e. relative to individual, his/her family, society, globe and the cosmos, there cannot be absolute peace or perfect peace. Everything is relative. No government is perfect, no culture is perfect and no individual is perfect. Hence, the concepts of freedom, fairness, recognition, respect, and justice are relative. Peace itself is relative to struggle and suffering. As long as there is life, there is struggle, and therefore no perfect peace. However, this does not mean that peace is not worth pursuing. In fact, its relativity only makes peace more valuable. In a world defined by suffering, it is more important than ever that we try to make peace wherever we can, even if it is relative to the situation.

In order to keep peace or resolve conflicts, it is not enough to change our laws, policies, and programs. We need action on a greater scale. We need to change the way we think about ourselves, our children, and our future. We need to promote the idea that all beings and all elements together constitute one planetary life and 
that there is natural equity in diversity. Beings are not equal in size, shape, and color, but they are equitable in the workings of their systems. If the diversity of life is understood in terms of its purpose, function and use, conflicts arising from disrespect of others' differences will decrease and peace will be promoted.

\section{Individual}

On the individual level, the goal is to resolve conflict between mind and body, health and illness, and between oneself and the world. The best way to do this is to participate in activities that increase a feeling of connection between the individual and the universe. Some activities have been proven to promote connectivity.

Religion can serve as an ethical guidepost for all earthly phenomena such as abuse, conflict, death, disease, disasters, negative emotions, and war. Though the answers to these negative phenomena manifest themselves in unique ways within differing religions, it is evident that practices of compassion, kindness, reverence, and respect towards oneself and others are relatively ubiquitous across religions. These positive actions suggest the inherent existence of human dignity in all religions. In addition, many religions emphasize the importance of the connection of humankind to the world around us.

The diversity of life is considered "the creation" by several religions, but also as "nature" by science. In appealing to the inner connection with the natural world, the biological theory of evolution can coexist peacefully with the world's religions.

Music and dancing are artistic disciplines which require controlled concentration and rigorous practice leading to synchronization within one's body. Hobbies, arts and crafts often work in the same way. Many people feel that it is therapeutic to create things and to pursue their own interests as a way to give them peace of mind.

Volunteering is one of the best ways for individuals to get involved in the community. Volunteers feel connected to other people and empowers them in realizing their self-worth in helping the community.

\section{Hindu-Buddhist Peace-Practices: Contribution to Humanity}

India's Hindu-Buddhist cultures have provided a vast array of methods to create inner peace and harmony. A significant aspect to these methods is the conceptualization and importance that Hindu philosophy places upon sound, and consequently, on words and music. Within this system, one may find great importance placed upon the chanting of certain syllables (such as the popular, "Aum"), in order to allow participants to achieve spiritual goals. Hindu-Buddhist practices used the power of words and mantras to invite deities and to please them (Junghare, 2014). They developed classical poetry of ragas to be sung during different times of the day-morning ragas, afternoon ragas and evening ragas and for laughter, cry, and sorrow, etc. Most often seen are devotional songs that are sung within the context of prayer or celebration. The singing of the devotional songs, called Bhajans, provide functions both in terms of religious and social well being of the individual participants (Babb, 1975). The devotional songs are closely linked to the cultural-religious philosophy of the land, specific events, days and celebrations, providing the context for singing and carrying out functions for meeting social needs and demands of common folks.

Since the Indian society is so diverse in nature, the educated pundits created a complex musical system of Ragas and Talas based on the hymns discussed in the ancient text of Sama Veda (Shankar, 1968). Specific days, months and even hourly time provide the context for the performance or playing of certain pieces or Ragas (Shankar, 1968). Thus, music serves as a method or tool for practitioners to achieve spiritual goals, most often associated with one's inner peace. 
Another method leading to inner peace and harmony can be found in classical Indian dance. In general terms, the dance tradition within India has had a long history of development and a complex relationship with other fine arts, especially music (Vatsyayan, 1963, pp. 33-38). Rooted in religious mythology and interconnected with poetry, rhythm, sound, and movement, Indian dance focuses on finding spirituality through theatrical interpretation. Yet this artistic discipline is not only a metaphysical path to finding a sense of balance within the body, it also represents a physical embodiment that requires hard work, practice and determination which lead to a physical sense of harmony within one's own body (Chatterjea, 2004, pp. 102-116). For the observer, devotional songs, prayers, epic poetry, and classical dances detail the histories and narrate the mythical events of Hindu mythology as a means of educating individuals. Devotional songs and dances can be seen as serving educational and entertainment functions for the community primarily and spiritual and psychological functions for the performer secondarily.

However, for personal health through inner peace and harmony, the yoga philosophy of India has developed a technique, known as yoga, derived from the Sanskrit root $y u j$, which means "yoke", "unite", or "join". Yoga refers to the supreme synchronization of the mind, body and soul (deep consciousness) through meditation, ritual, and physical manipulation of the body (Eliade, 1958; Puligandla, 1975). Yoga is at least 5,000 years old, coinciding with the discovery of the vast Indus civilization and the excavation of Mohenjodaro and Harappa starting in 1920 (Hopkins, 1971). Yoga has significantly evolved from its inception, within India itself and especially once it was adopted by the west. Modern yoga began in the late 1800's when Swami Vivekananda presented the teachings of his guru Ramakrishna Paramahamsa at the Parliament of Religions in Chicago in 1893.

The classical period of yoga refers to the period of Yoga-Sutra written by Patanjali in approximately the second century A.D. (Eliade, 1958). Patanjali defined yoga as "the cessation of the fluctuating modalities of mind". The yoga of Patanjali, known as Raja-Yoga, the king of the yogas, provides the foundation to all other kinds of yogas, including those of Buddhism's Zen meditation. In fact, the Sanskrit word dhyanna meaning "concentration" or "meditation" first became Chen in Chinese and then Zen in Japanese.

Raja yoga is also known as "eight-limbed" yoga (Puligandla, 1975). These limbs are: Yama (ethical values, control), Niyama (observances of purity, tolerance and study), Asanas (physical exercises), Pranayama (breathing), Pratyahara (withdrawal of the senses before meditation), Dharana (concentration), Dhyana (meditation) and Samadhi (ecstasy, subject becoming object, the state of total freedom). Modern yoga focuses mostly on the physical poses of yoga and less on its spirituality.

Post-classical yoga focused on rejuvenating and preserving (even immortalizing) the body (Eliade, 1958). This led to the creation of Hatha and Tantric yoga, both of which focus on purifying the body in order to attain Samadhi, the perfect union of mind, body and spirit, i.e. pure consciousness and pure happiness_- "Absolute Peace".

Mahatma Gandhi's extraordinary life experiences and his peace movement received its inspiration from the book Bhagavad Gita (Gandhi, 2009). His Gita is a call to detached service to others and devotion to God. Man is not at peace with himself until he has become like unto God. The endeavor to reach this state is supreme, and this is self-realization. Self-realization is the subject of the Gita, as it is of all scriptures. The Gita's primary message for attaining peace is: "Do your allotted work but renounce its fruit. Be detached and work. Have no desire for reward and work." Gandhi justified this teaching by saying, "When there is no desire for fruit, there is no temptation for untruth or himsa (Gandhi, 2009, p. 22). 
Gita is not a collection of Do's and Don'ts. What is lawful for one may be unlawful for another. What may be permissible at one time, or in one place, may not be so at another time, and in another place. Desire for fruit is the only universal prohibition. Desirelessness is obligatory. (Gandhi, 2009, p. 24)

The message of this text is simplicity of life, i.e. less focus on materialism, relatively brings us more peace. In Gandhi's words, "the less we possess, the less we want, and the better we are. The more we possess the more we want, and the worst we are."

\section{Communal/Societal/Cultural Peace}

On the community/society level the nature of problems change. The main issue at this level is inequality, and inequality stems from differences in: race, gender, sex, age, religion, class, caste, ethnicity, etc. Fortunately, we can combat these more complex issues by promoting peace through peaceful means. Gandhi's methods are particularly useful here to actually create change in society.

1. The first of Gandhi's philosophies on this subject is insistence on truth. He believed that all societal change must be rooted deeply in the truth in order for peaceful change to occur. This is the place where we see how peace cannot flourish without ethics, in this case being truthful (Gandhi, 2009).

2. Gandhi was also revolutionary in his philosophy of promoting change through nonviolence and nonviolent non-cooperation (Gandhi, 2001). After all, peaceful resolution to societal issues should never ever include violence since it only exacerbates the problem and doesn't help the cause of creating peace between people.

3. Next, we have the philosophy of creating policies, rules, and laws through legislation for guarding the welfare of all beings as well as creating an "all-inclusive" justice system - and not one that allows the rich and elites to have special privileges.

4. The last philosophy focuses on appealing to the inner conscience of the people for doing the right thing by creating dialogues between religions, ethnicities, and between rich elites and common people. The more often these people communicate, the more likely they are to understand each other and be able to work towards a common goal.

\section{Universal Peace}

Universal peace is not so much an achievable level of peace as it is an idea. Sometimes it can help someone to reach inner peace by standing back and simply determining his/her place in the universe. In short, universal peace transcends all cultures, all people, and all beings by focusing on the intrinsic value of each and every existence through recognition and respect for the cosmos as a whole, and an individual as its part.

\section{Concluding Recommendations}

The most important suggestion this paper makes is to implement a diversity-ethics-peace curriculum into the educational system so that children are familiar with these ideas starting at a young age. Then they will grow to be more peaceful adults and more mindful global citizens.

At the university level, it is necessary to create the academic discipline of Diversity-Ethics-Peace Studies which identifies and analyses violent and nonviolent behaviors, as well as the structural mechanisms attending violent and nonviolent social conflicts. This curriculum is to better understand the processes leading to a more desirable human condition. This interdisciplinary study will aim at the prevention, de-escalation, and solution 
of conflicts related to diversity of race, gender, ethnicity, age, among other factors. This will contrast with war studies (polemology), directed at the efficient attainment of victory in conflicts. Disciplines involved in diversity-ethics-peace may include political science, geography, economics, psychology, sociology, international relations, history, anthropology, linguistics, religious studies, gender studies, and law, as well as a variety of other disciplines.

This paper suggests not only trans-rational, trans-cultural, but also trans-disciplinary approach, which combines the mechanistic understanding of modern peace with those universal and cosmological visions oriented towards the establishment and maintenance of harmonious relations between humans, nature and cosmos.

In addition, we can lobby for laws and treaties focusing on diversity and peace, and work to implement these laws through global organizations that already exist, like the United Nations. Of course, the most productive thing we can do now is to simply take action wherever we can at all levels of society. If everyone conducted one random act of kindness a day, the positive results would be incalculable. Or, as Gandhi said, we need to "be the change we want to see in the world".

The best way to avoid conflict is to be aware of our own attitudes, beliefs, and behaviors when we interact with other people and with the environment. We need to practice the philosophy of diversity based on common ground, yet recognize, accept and respect differences, including the diverse perceptions of the concept of peace.

\section{Acknowledgement}

I thank Marina Challen for presenting the earlier version of this paper at The 15th International Conference of Diversity in Organizations, Communities and Nations, Hong Kong, July 15-17, 2015.

\section{References}

Babb, L. A. (1975). The divine hierarchy. New York, NY: Columbia University Press.

Bagish, H. H. (1990). Confessions of a former cultural relativist. In Guilford (Ed.), Annual editions anthropology, $90 / 91$ (pp. 30-37). CT: The Dushkin Publishing Group, Inc.

Bidney, D. (1959). The philosophical presuppositions of cultural relativism and cultural absolutism. In Leo R. Ward (Ed.), Ethics and the social sciences (pp. 51-76). Notre Dame, IN: Notre Dame.

Chatterjea, A. (2004). In search of a secular in contemporary Indian dance: A continuing journey. Dance Research Journal, 36(2), $102-116$

Dietrich, W. (2006). A call for many peaces. In W. Dietrich, J. Echavarria, \& N. Koppensteiner (Eds.), Key texts of peace studies (pp. 282-305). Vienna: LIT Verlag.

Dietrich, W. (2012). Interpretations of peace in history and culture. London: Palgrave Macmillan.

Eliade, M. (1958). Yoga; Immortality and freedom. New York, NY: Pantheon.

Galtung, J. (1996). Peace by peaceful means: Peace and conflict, development and civilization. London: Sage Publications.

Gandhi, M. K. (2009). The Bhagavad Gita. Berkeley, California: North Atlantic Books.

Gandhi, M. K. (2001). Non-violent resistance (Satyagraha). Mineola, New York: Dover Publications.

Herskovits, M. J. (1973). Cultural relativism: Perspectives in cultural pluralism. New York: Vintage Books.

Hopkins, T. J. (1971). The Hindu religious tradition. Belmont, CA: Dickenson Publishing Company.

Junghare, I. Y. (2015). The ethical power of word. The International Journal of Diverse Identities, 15(4), 27-38.

Kant, I. (1999). Toward perpetual peace. In Practical philosophy-Cambridge edition of the works of Immanuel Kant. (M. J. Gregor, Trans.). Cambridge: Cambridge University Press.

Puligandla, R. (1975). Fundamentals of Indian philosophy. New York: Abingdon Press.

Rollin, B. (2006). Science and ethics. Cambridge, England: Cambridge University Press.

Rosado, C. (1994). The concept of cultural relativism in a multicultural world. Retrieved from October 21, 2015, http://www.cabrillo.edu/crsmith/CulturalRelativism.pdf 
Shankar, R. (1968). My music, my life. C. H. Simon (Ed.). New York, NY: Simon and Schuster.

Shankar, R. (1968). The sounds of India. All Music. Retrieved August 15, 2015.

Turner, J. H. (1986). The structure of sociological theory. Belmont, CA: Wadsworth Publishing Company.

Vatsyayan, K. (1963). Notes on the relationship of music and dance in India. Ethnomusicology, 7(1), 33-38.

Wilmerding, J. (2010). The theory of active peace. Retrieved October 13, 2015.

Wilson, E. (2006). The creation. New York, NY: W. W. Norton and Company.

Witzel, M. (2003). Vedas and Upanisads. In G. Flood (Ed.), The blackwell companion to Hinduism (pp. 68-101). Malden, MA: Blackwell. 